\title{
症例報告
}

\section{胎児心エコー所見をもとに早期娩出し救命できた ハイリスク仙尾部奇形腫の胎児例}

\author{
高橋 実穂 $^{1)}$, 堀米 仁志 $^{1)}$, 加藤 愛章 ${ }^{1)}$, 野崎 良寛 ${ }^{1)}$, 林 立申 ${ }^{1)}$, \\ 中村 昭宏 $^{1)}$, 齋藤 誠 ${ }^{1)}$, 濱田 洋実 ${ }^{2)}$, 瓜田 泰久 ${ }^{3)}$, 須磨嵪 亮 ${ }^{1)}$ \\ 1) 筑波大学医学医療系小児科 \\ 2) 筑波大学医学医療系産婦人科 \\ 3) 筑波大学医学医療系小児外科
}

\section{Successful Preterm Delivery of a Fetus with High-risk Sacrococcygeal Teratoma Based on Fetal Echocardiographic Findings}

\author{
Miho Takahashi-Igari ${ }^{1)}$, Hitoshi Horigome ${ }^{1)}$, Yoshiaki Kato ${ }^{1)}$, Yoshihiro Nozaki ${ }^{1)}$, Lisheng Lin ${ }^{1)}$, \\ Akihiro Nakamura' ${ }^{1}$, Makoto Saito ${ }^{1}$, Hiromi Hamada ${ }^{2}$, Yasuhisa Urita ${ }^{3)}$, and Ryo Sumazaki ${ }^{1)}$ \\ ${ }^{1)}$ Department of Child Health, Faculty of Medicine, University of Tsukuba, Ibaraki, Japan \\ 2) Department of Obstetrics and Gynecology, Faculty of Medicine, University of Tsukuba, Ibaraki, Japan \\ ${ }^{3)}$ Department of Pediatric Surgery, Faculty of Medicine, University of Tsukuba, Ibaraki, Japan
}

\begin{abstract}
A solid giant sacrococcygeal teratoma (SCT) may cause high-output heart failure in a fetus. The mortality rate increases with the development of fetal hydrops. In this study, we report a case of a rapidly growing fetal SCT, in which early delivery was carried out based on fetal echocardiography findings. Tumor resection immediately after delivery resulted in survival of the baby. The mother was referred to our hospital at 19 weeks of gestation. The tumor length increased rapidly from $11.2 \mathrm{~cm}$ at 29 weeks to $15.6 \mathrm{~cm}$ at 30 weeks. Fetal magnetic resonance imaging showed a large, predominantly solid type of SCT without extension into the pelvic space (Altman type I). At 30 weeks, the fetal combined cardiac output was elevated to $1,350 \mathrm{~mL} / \mathrm{kg} / \mathrm{min}$, but no signs of hydrops were observed. After repeated evaluation with fetal echocardiography, a cesarean section was conducted at 32 weeks and 3 days. This decision was based on progressive cardiomegaly, development of right ventricular dysfunction and tricuspid regurgitation, and abnormal distribution of cardiac output. Intervention timing plays a critical role in the survival of a fetus with high-risk SCT, and repeated echocardiographic evaluation of the fetal cardiovascular dynamics is essential.
\end{abstract}

Keywords: giant sacrococcygeal teratoma, high-output heart failure, fetal echocardiography, preterm delivery

充実性の巨大な胎児仙尾部奇形腫は高心拍出性心不全を伴いやすく, 胎児水腫に至ると致死率が上が る. 急速に増大した仙尾部奇形腫を伴う胎児に対し, 胎児心エコー所見に基づいて早期娩出を計画し, 分娩直後に腫瘍摘出術を施行し, 合併症なく救命できた胎児例を報告する. 症例は妊娠 19 週の胎児. 妊娠 28 週から 30 週にかけて腫瘍長径が $11.2 \mathrm{~cm}$ から $15.6 \mathrm{~cm}$ へと急速に増大した. 胎児 MRI では腫 瘍は充実性優位で骨盤腔内への進展のないタイプ（Altman I 型）であった． 30 週の胎児心エコーでは 胎児水腫はないが, 両心拍出量は $1,350 \mathrm{~mL} / \mathrm{kg} / \mathrm{min}$ と著明に増加していた．経時的に胎児心エコーを 施行し, 心拡大の進行, 右室収縮能の低下, 三尖弁閉鎖不全の出現, 心拍出量の分布の変化を契機に

2016 年 3 月 19 日受付, 2016 年 5 月 25 日受理

著者連絡先：干305-8575 茨城県つくば市天王台 1-1-1 筑波大学医学医療系小児科 高橋実穂 doi: $10.9794 /$ jspccs.32.328 
32 週 3 日に帝王切開と腫瘍摘出術を施行した結果, 後遺症なく胎児を救命することができた. ハイリ スクの胎児仙尾部奇形腫は治療介入のタイミングが胎児の予後を左右するため, 胎児心エコーによる 継時的な血行動態評価が不可欠と考えられた。

はじめに

仙尾部奇形腫は新生児腫瘍の中で最も頻度が高く, 出生 $35,000 \sim 40,000$ 人に 1 人とされている ${ }^{1)}$. 組織 型はほとんどが良性であり，摘出術により予後は良好 であることが多い.しかし, 胎児診断された大きな仙 尾部奇形腫では胎児・新生児死亡率が高い ${ }^{2)}$. 巨大で 急速に増大する，充実成分の多い仙尾部奇形腫はハイ リスクである。これは腫瘍への Vascular steal による 高心拍出性心不全や胎児水腫, 羊水過多による早産, 腫瘍内出血, 腫瘍破裂, 母体の Mirror 症候群などを きたすためである. 本邦の出生前診断された仙尾部 奇形腫の調査研究では, 分娩週数 31 週未満が胎児・ 新生児死亡の最大のリスク因子であると報告されて いる ${ }^{3)}$. 児の未熟性の問題は避けては通れないが, 胎 児水腫にいたる前に, 積極的に早期娩出（27〜32 週） して治療介入することにより, 予後を改善できる症例 が含まれることが報告されている ${ }^{4)}$. 早期娩出のタイ ミング, 治療介入の方法については腫瘍自体の評価以 外に, 胎児心エコーでの継続的な血行動態の評価が重 要である.
症例

症例は胎児慰部腫瘤を指摘されて当院産婦人科に紹 介された妊娠 19 週の胎児である. 胎児エコーでは仙 尾部奇形腫 (sacrococcygeal teratoma: SCT) が疑わ れ, 腫瘍長径は $11.2 \mathrm{~cm}$ (28 週 2 日) から, $15.6 \mathrm{~cm}(30$ 週 2 日）と増大した。胎児 MRI では腫瘍は仙尾部か ら尾側に分葉状に突出しており, 骨盤内への進展はな かった. 腫瘍は T2 強調画像で比較的高信号を呈し, 内部に微小囊胞構造をもつ充実性成分が主体であつ た. 脂肪を含んでおり奇形腫に矛盾しない所見であっ た. 充実成分内部に $\mathrm{T} 1$ 強調画像で高信号, T2 強調 画像で低信号を呈する部分があり腫瘍内出血を伴って いる可能性も考えられた。また充実性成分の辺縁に大 きな囊胞成分が認められたが，羊水と比べて $\mathrm{T} 1$ 強調 画像での信号が高いため, 囊胞内成分は血性である可 能性も考えられた。 以上から充実成分主体の SCT で AltmanI 型と考えられた（Fig. 1).

妊娠 30 週 3 日に胎児心臓外来に紹介された。 心 臓の構造異常はなかった. 総心横径（Total cardiac dimension: TCD) $35.7 \mathrm{~mm}$, 心胸郭断面積比（Cardio-

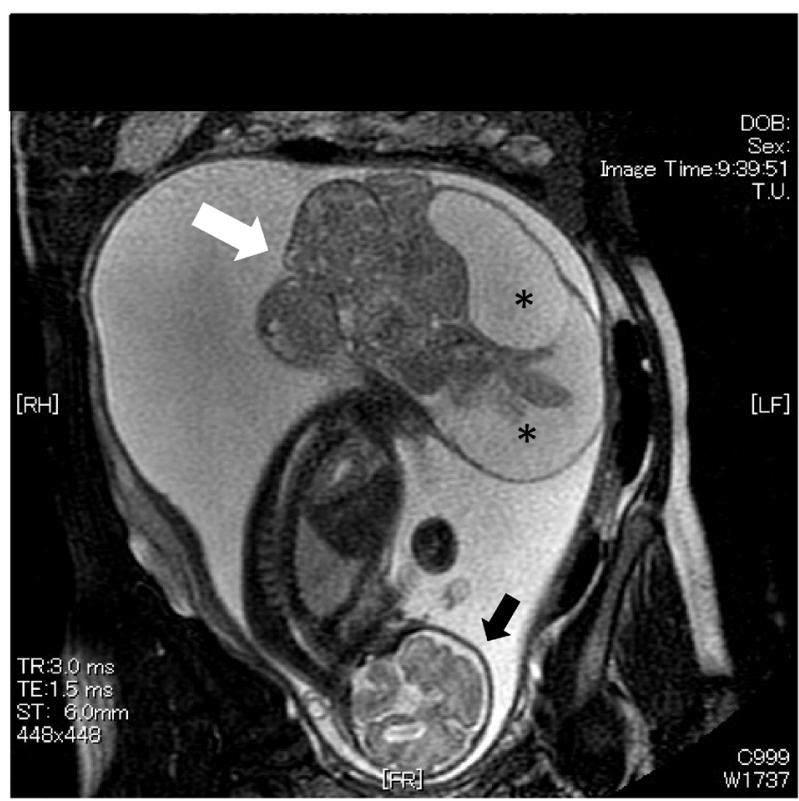

Fig. 1 Fetal magnetic resonance imaging sagittal view at 30 weeks and 3 days of gestation

The image shows a huge sacrococcygeal teratoma (white arrow) without extension into the intra-pelvic space (Altman type I) on the opposite side of the fetal brain (black arrow). The tumor predominantly comprised a solid component with cystic lesions (asterisks). 
(A)

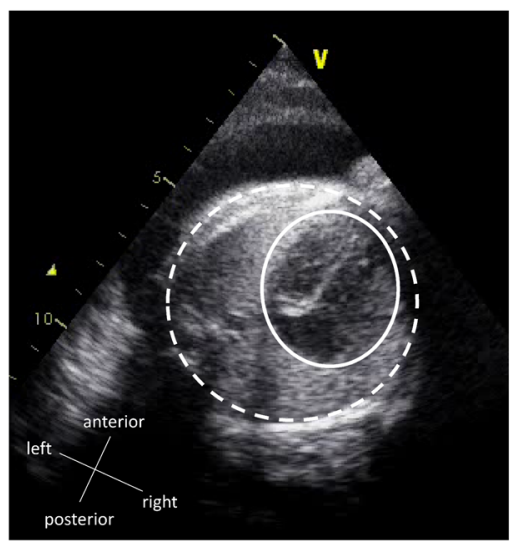

(B)

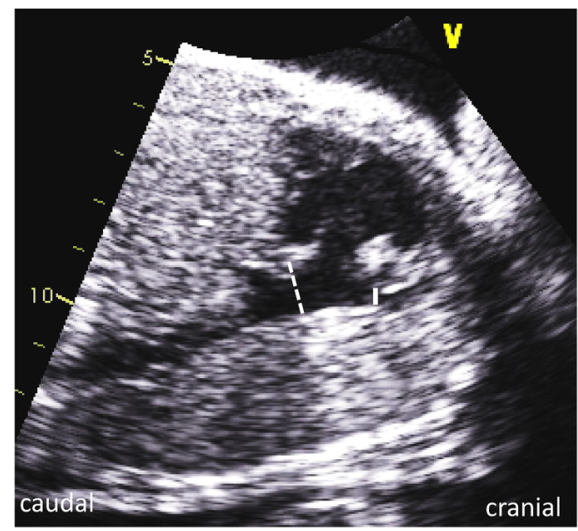

Fig. 2 Fetal echocardiography at 30 weeks and 3 days of gestation

(A) In the four-chamber view, the cardiothoracic area ratio is $36 \%$ (mild cardiomegaly), despite marked elevation in combined cardiac output. (B) In the sagittal view, the inferior vena cava appears to be dilated compared with the superior vena cava.

thoracic area ratio: CTAR）36\% と心拡大は軽度であっ た（>35\%：心拡大). 四腔断面像では左右のバラン スはよく房室弁逆流は認められなかった（Fig. 2)。し かし, 上大静脈径 $4.5 \mathrm{~mm}$ に比し, 下大静脈径 $7.5 \mathrm{~mm}$ と拡張していた. 2D ドプラ法から求めた両心拍出量 (Combined cardiac output: CCO) は $1,350 \mathrm{~mL} / \mathrm{kg} /$ $\min$ と著明に増大していた. 右室拍出量 (RVCO) : 左 室拍出量 $(\mathrm{LVCO})=67: 33$ であり, 心拍出の分布は ほぼ正常範囲であった。この時点では右室径短縮率 （RVFS）30\%, 左室径短縮率（LVFS）37\% と保たれ ていた. 臍帯動脈および静脈のドプラパターンは正 常範囲であり, 胎児水腫は認められなかった. BPS （Biophysical profile score）10/10であった. 羊水過多 が認められた.

腫瘍のエコーおよび MRI 所見, 胎児心エコー所 見からハイリスクSCT であると判断し, 治療介入の 検討を開始した. 胎児心エコー所見の推移を Table 1 に示す. 31 週 4 日では CTAR $43 \%$ と増加し, CCO $1,200 \mathrm{~mL} / \mathrm{kg} / \mathrm{min}(\mathrm{RVCO}: \mathrm{LVCO}=62: 38)$, RVFS 33\%, LVFS 33\%（>28\%）であった. 軽度ではある が三尖弁閉鎖不全が認められた. 胎児水腫は認められ なかった. 32 週 0 日には心房中隔瘤を形成して抢り 卵円孔が狭小化したことに加え, 高心拍出状態のた めに相対的卵円孔狭窄が起こっている機序も推測され た. RVCO: $\mathrm{LVCO}=86: 14$ と心拍出分布が極端に右 室側へ偏位し，RVFS は $22 \%$ と低下が認められた。 これは卵円孔狭小化により右室前負荷が著明に増大 し，その結果右室は機能不全を起こし，収縮能低下に 至ったと考えられた。右室が担う心拍出量が多いため
Table 1 Changes in parameters and findings by fetal echocardiography (present case)

\begin{tabular}{lccc}
\hline \multirow{2}{*}{$\begin{array}{c}\text { Parameters and } \\
\text { findings }\end{array}$} & \multicolumn{3}{c}{ Gestational age at examination } \\
\cline { 2 - 4 } & 30w3d & 31w4d & 32w0d \\
\hline CTAR (\%) & 36 & 43 & 44 \\
CCO (mL/kg/min) & 1,350 & 1,200 & 1,030 \\
RVCO: LVCO & $67: 33$ & $62: 38$ & $86: 14$ \\
RVFS/LVFS (\%) & $30 / 37$ & $33 / 33$ & $22 / 38$ \\
MCA-PSV (cm/s) & 71 & 72 & 40 \\
Hydrops & - & - & - \\
Other findings & - & Tricuspid & FO restriction \\
& 9 & regurgitation \\
CVPS & 9 & 8
\end{tabular}

CTAR: Cardiothoracic area ratio, CCO: combined cardiac output, RVCO: right ventricular cardiac output, LVCO: left ventricular cardiac output, MCA-PSV: middle cerebral artery-peak systolic velocity, FO: foramen ovale, CVPS : Cardiovascular profile score (Huhta, 2005). 5 Categories $=$ (1) hydrops (2) venous Doppler (3) CTAR (4) cardiac function(TV/MV) (5) arterial Doppler, Full score: 10 points $=$ no abnormal signs.

にCCO の絶対值も低下傾向になったと判断した．産 婦人科, 小览外科, 小览科 (新生览, 循環器), 麻酔 科と調整の上，32 週 3 日に帝王切開に至った. 巨大 な SCT が認められた。腫瘍右側壁から少量出血があ り羊水は血性であったが，幸いにも腫瘍の破綻はな かった (Fig. 3).

Apgar スコアは 1 分 1 点, 5 分 3 点であった. 生後 1 分 20 秒で気管挿管し, 生後 1 分 30 秒で末梢静脈ラ インを確保した。徐脈に対して胸骨圧迫やボスミン静 


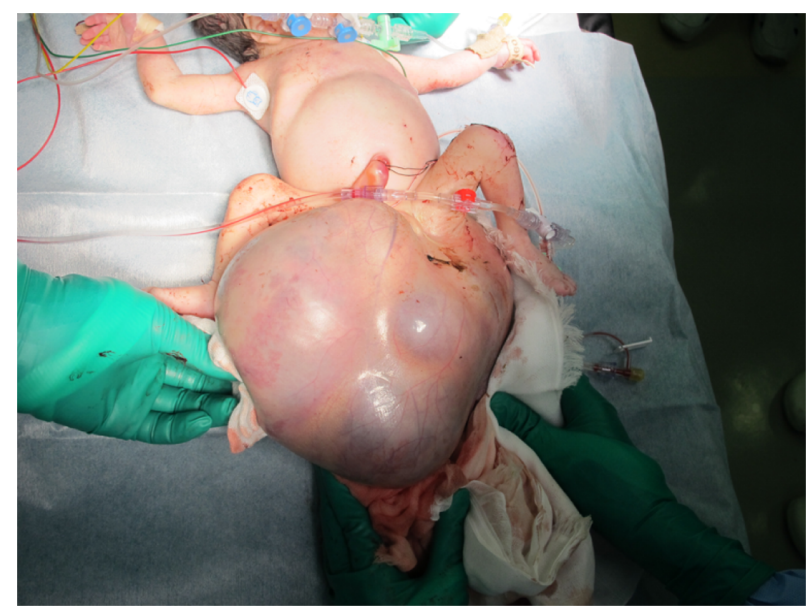

Fig. 3 A large sacrococcygeal teratoma $(22 \times 25 \times$ $14 \mathrm{~cm}$ ) before resection

脈内投与を要した. 生後 9 分の心エコーで心臓の構造 や収縮能の低下がないことを確認した. 生後 22 分に 臍帯動脈ラインを留置した. 臍帯静脈カテーテルは挿 入できず, 最終的に内頸静脈からのカットダウンに切 り替えた. 生後 77 分にサーファクタント気管内投与 した. 短時間の両親との面会の後, 蘇生室から手術室 へ移動した. 生後 93 分で SCT 切除術が開始された. 同定した正中仙骨動静脈の結紮切離により循環動態が 安定し, 最終的に 3 時間 19 分で手術は終了した. 最 終出血量は $270 \mathrm{~mL}$ で, 術中に濃厚赤血球 $580 \mathrm{~mL}$, 新鮮凍結血漿 $180 \mathrm{~mL}$, 濃厚血小板 $90 \mathrm{~mL}$ の輸血を要 した. 腫瘍重量 $1,800 \mathrm{~g}(22 \times 25 \times 14 \mathrm{~cm})$ で, 骨盤内 への進展はなく Altman I 型で, 病理診断は未熟奇形 腫（grade 3）であった.

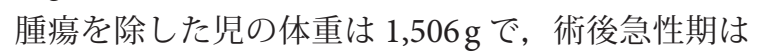
ドーパミン，ホスホジエステラーゼ III 阻害薬，ハイ ドロコーチゾンの投与やアルブミン・生理食塩水など の負荷を要した。次第に循環呼吸は安定し, 日齢 13 に気管チューブを抜管し，日齢 20 に二相性持続陽圧 呼吸療法（SiPAP）を離脱した。 日年齢 57 に $2,100 \mathrm{~g}$ で退院した. 生後 2 か月（修正 40 週）の頭部 MRI では左小脳半球と左尾状核近傍にわずかな旧出血巣が 認められたのみであった，四肢の運動障害はなく， 排便や排尿の問題も今のところない. 出生時 AFP 639,520 ng/mL と著明に上昇していたが, 切除後はす みやかに低下し, AFP $29.2 \mathrm{ng} / \mathrm{mL}$ で, CT で再発や転 移を疑う所見はない.

\section{考察}

出生後に診断された SCT に比べ，胎児 SCT の予後 は不良である ${ }^{5)}$. 人工中絶を除くと $46 \%$ が胎内ある いは新生児期に死亡している.

2000 年から 10 年間における本邦で出生前診断され た仙尾部奇形腫の後方視的検討によれば， 31 週未満 に出生した症例, 胎児水腫徵候の有無, 腫瘍の大き さ, 腫瘍増大速度, 腫瘍の構成成分が予後予測因子で あった ${ }^{3)}$. 腫瘍の大きさについては, 最大径 $12 \mathrm{~cm}$ 以 上の症例の死亡率が有意に高く, 腫瘍最大径/児頭大 横径（BPD） 11.6 が予後不良であった. 腫瘍増大速 度については, 腫瘍最大径の増加率 $\geqq 0.6 \mathrm{~cm} /$ 週が予 後不良であった。 また, 腫瘍構成成分では充実型, 霊 胞型, 混合型のうち, 充実型あるいは混合型のうち 充実優位型が予後不良であった。本症例でも腫瘍最 大径/BPD は 2.6 , 腫瘍増大速度 $2.2 \mathrm{~cm}$ /週, 充実優位 型であり，これらの予後不良因子に該当した。腫瘍容 積増加率 $\left(\mathrm{cm}^{3} /\right.$ 週 $) \geqq 61$ だと予後不良であり, さら に $165\left(\mathrm{~cm}^{3} /\right.$ 週 $)$ だと子宮内死亡のリスクが非常に高 い ${ }^{6}$. 最近は MRI 計測值の予後不良因子の報告もあ $り^{7,8)}$, 腫瘍容積指数 $\left(\mathrm{cm}^{3} / \mathrm{g}\right)=$ 腫瘍容量/推定体重 0.12 , 腫瘍充実成分容積指数 $\left(\mathrm{cm}^{3} / \mathrm{g}\right)=$ 充実成分/推 定体重 $\geqq 0.09$ などである. Table 2 にそのまとめを示 す。本症例の組織型は未熟奇形腫であり, 再発や転移 などを含めた死亡率に関係するため ${ }^{9)}$, 注意が必要で ある。

Children's Hospital of Philadelphia (CHOP) の検 討では，ハイリスク胎児 SCT は “watchful waiting” の policyでは救命できないため, 症例を選んでむしろ 27〜32 週で早期娩出することで予後を改善できると している ${ }^{4)}$. 28 週未満で高心拍出性心不全による胎 児水腫の初期なら胎児手術（直視下腫瘍切除術）に より救命の可能性があるが, 骨盤腔への進展がない か, あっても軽度である AltmanI 型や II 型で, かつ 重症の胎盤水腫がなく, Mirror 症候群などの母体合 併症のない症例に限られる. 28 週以降あるいは 27 週 以降でも高心拍出性心不全の進行がみられる場合, 腫瘍内出血がみられる場合, ドプラや BPS や心拍な ど胎児 well-being に異常がある場合, 羊水過多のた めに分娩がコントロールできない場合は，子宮内死 亡を回避するために帝王切開で早期娩出をすること を提案している，母体あるいは胎盤に問題がなけれ ば EXIT（Ex-utero intrapartum treatment）も考慮さ れるとしている. EXIT とは帝王切開時に胎盤循環を 維持した状態で胎児の気道を確保することであり，血 
Table 2 Reports of prognostic factors in sacrococcygeal teratoma

\begin{tabular}{|c|c|c|c|c|}
\hline Factor & Modality & Findings or Index & Poor prognosis & Our case \\
\hline Hydrops & US & Skin edema+effusion & yes & no \\
\hline \multirow[t]{2}{*}{ Size of tumor } & US & Maximum diameter of tumor/BPD & $\geqq 1.6$ & 2.6 \\
\hline & MRI/US & Tumor volume/EFW $\left(\mathrm{cm}^{3} / \mathrm{g}\right)$ & $\geqq 0.12$ & N.D \\
\hline \multirow[t]{2}{*}{ Tumor growth rate } & US & Maximum diameter growth rate (cm/week) & $\geqq 0.6$ & 2.2 \\
\hline & US & Tumor volume growth rate $\left(\mathrm{cm}^{3} /\right.$ week) & $>61$ & N.D \\
\hline \multirow[t]{5}{*}{ Tumor components } & US & Cystic ( $\geqq 90 \%)$ & Solid or predominantly solid & Predominantly solid \\
\hline & & Predominantly cystic (50-90\%) & & \\
\hline & & Predominantly solid (50-90\%) & & \\
\hline & & Solid ( $\geqq 90 \%)$ & & \\
\hline & MRI & Solid tumor volume/EFW $\left(\mathrm{cm}^{3} / \mathrm{g}\right)$ & $>0.09$ & N.D \\
\hline
\end{tabular}

US: ultrasound, MRI: magnetic resonance imaging, BPD: biparietal diameter, EFW: estimated fetal weight, N.D: not done.

Table 3 Reports of fetal echocardiographic findings of cardiac output and hydrops (including in sacrococcygeal teratoma)

\begin{tabular}{|c|c|c|c|}
\hline Author (year) & Numbers of cases & Study parameters & Results \\
\hline $\begin{array}{l}\text { Hofsraetter, et al. } \\
\text { (2006) }\end{array}$ & $n=100$ & Hydrops and CVPS & $\begin{array}{l}\text { Median CVPS was } 6 \text { in hydrops fetalis. } \\
\text { CVPS } \geqq 8 \text { survived in all case. }\end{array}$ \\
\hline $\begin{array}{l}\text { Statile, et al. } \\
\text { (2013) }\end{array}$ & $n=35$ & CCO and CVPS & $\begin{array}{l}\text { An inverse relationship between CCO and CVPS in the } \\
\text { fetus with high cardiac output } .13 \text { fetuses with CPVS }<8 \text {, } \\
11 / 13 \text { had a CCO }>625 \mathrm{~mL} / \mathrm{kg} / \mathrm{min} \text {. }\end{array}$ \\
\hline Rychik (2004) & $\begin{array}{c}27 \text { fetuses with } \\
72 \text { echocardiograms }\end{array}$ & CCO and IUFD & $\begin{array}{l}\text { Fetuses with high output (CCO }>750 \mathrm{~mL} / \mathrm{kg} / \mathrm{min}) \text { and/ } \\
\text { or evidence of reversal of diastolic flow in the umbilical } \\
\text { artery was died in utero. }\end{array}$ \\
\hline $\begin{array}{l}\text { Tongsong, et al. } \\
\text { (2010) }\end{array}$ & $n=69$ & $\begin{array}{l}\text { Venous Doppler studies in } \\
\text { low-output and high-output } \\
\text { hydrops }\end{array}$ & $\begin{array}{l}\text { The umbilical vein pulsations were found in } 78.9 \% \text { of } \\
\text { the fetuses with low-output hydrops but only } 28.0 \% \text { of } \\
\text { fetuses in high-output group. }\end{array}$ \\
\hline
\end{tabular}

CVPS: Cardiovascular profile score (Huhta, 2005). 5 Categories=(1) hydrops (2) venous Doppler (3) CTAR (4) cardiac function (TV/ MV) (5) arterial Doppler. Full score: 10 points =no abnormal signs.

行動態が安定した中で, より迅速に腫瘍の治療にのぞ めるメリットがある. 胎児治療については open fetal surgery 以外にも，侵襲が少ないレーザー凝固や高周 波凝固 (radiofrequency ablation: RFA), コイル塞栓 などに期待があるが，子宮内死亡や早産などもみら れ, 胎児水腫に陥った 30 週未満での出生は予後が非 常に悪い ${ }^{10)}$. 本症例でも結果として 32 週での分娩で あったこと, かつ胎児水腫になる前に娩出したことが 救命の第一歩につながった. 分娩直後の腫瘍破綻から 出血をきたし手術まで到達できない症例や, 術中術後 に出血が原因で死亡した症例もあり，出血をいかにコ ントロールするかも救命のうえでは重要である ${ }^{3)}$. 出 生後に手術に先行して塞栓術や RFA を行って出血を コントロールする試みもなされているが, アプローチ の問題, 時間的制約, 急激な高カリウム血症などの問 題もある ${ }^{11-13)}$. 本症例ではその余裕はなく，むしろ 手術時間を短縮するためには塞栓術や RFA は選択し
なかった。

胎児エコーやMRI の計測などからハイリスク SCT を早くから認識し，高心拍出状態であることを確認す ることは，婏出時期を計画する上で非常に重要であ る. 早期婏出といっても 27〜32 週には幅があり, 胎 児心不全そして胎児水腫の前兆をいかにとらえるかと いうことが求められるが，実際には何を指標にしたら いいか明確な答えはない. CCO と CTAR は相関して 増加するが ${ }^{17) ， は ゙ ら つ き か ゙ あ る た め ~ C T A R ~ の み て ゙ は ~}$ 心不全徵候とはいえない。高心拍出状態では心拡大は 代償機転でもあり，心拡大の程度や心不全の有無は心 拍出量だけできまるわけではない，高心拍出性心不全 は心臓の代償不全がくる前に胎児水腫に進行する ${ }^{18)}$ ため，いかに胎児水腫になる前に分娩するかは難し い. 胎児水腫と胎児心エコー所見のいくつかの報告 を Table 3 にまとめた。 原因に関係なく, 胎児水腫と CVPS（Cardiovascular Profile Score）は関係があり, 
胎児水腫例の CVPS の中央值は 6 点で，8 点以上だと 全例生存している ${ }^{14)}$. CVPS は Huhta が提唱したス コアで，(1)胎児水腫の有無（腔水症，皮下水腫）(2)静 脈波形 (臍帯静脈, 静脈管) (3)心胸郭断面積比(4)心機 能（RVFS,LVFS あるいは全収縮期 TR あるいは MR） (5)動脈波形 (臍帯動脈) の 5 項目について各 2 点満 点で（合計 10 点）計算する. 值が低いほど状態が悪 いことを意味する. 胎児心不全の総合評価として推奨 されており, 点数を追跡することで心不全の悪化を とらえる ${ }^{15)}$. 両心拍出量 (Combined cardiac output: CCO）が多いほど CVPS が低くなることが報告され ており ${ }^{16)}$, CVPS が低くなれば高心拍出状態がすす んでいることになる. 胎児の CCO の正常值は 425〜 $550 \mathrm{~mL} / \mathrm{kg} / \mathrm{min}$ といわれているが, CCO が $750 \mathrm{~mL} /$ $\mathrm{kg} / \mathrm{min}$ を超える症例や, 臍帯動脈の拡張期逆流の あった症例は子宮内死亡が多いと報告している ${ }^{17)}$. 低心拍出性心不全・胎児水腫とは違って, 高心拍出 性心不全・胎児水腫は, 臍帯静脈の拍動は必ずしも 認められない ${ }^{18)}$. 高心拍出状態では静脈管の Preload index は有意に低いことから, 臍帯静脈の拍動は中心 静脈圧の上昇を示しておらず, 臍帯静脈の拍動は指標 になりにくい. 本症例でも相当の高心拍出状態であっ たものの, 臍带静脈の拍動はみられなかった. しかし 心拡大の進行, 右心室径短縮率の低下, 三尖弁閉鎖不 全がみられた時点で CPVS は 9 点から 8 点に低下し, さらに正常の心拍出分布から外れた右室拍出量の増加 がみられたことに注意し, 拡張期途絶や胎児水腫のな い状態で計画的に娩出できた。本症例ではハイリスク SCT と判断し早期娩出にそなえて入院管理にした。 NST（non-stress test）と母体合併症の有無の評価を 毎日行い, 隔日で産科医がエコーで腫瘍の変化, 胎児 well-being, CTAR, 腔水症の有無を評価した. 小児 循環器医は胎児心エコーによる血行動態の詳細な評価 を最低週 1 回は行い, その所見に応じて間隔を短くし た．胎児心エコーのフォローアップ間隔は症例によっ て一定ではないものの, 血行動態の変化に着目し密に フォローする必要があると思われた.$$
\text { 結語 }
$$

ハイリスク仙尾部奇形腫の胎児に対して, 胎児心エ コー所見をもとに早期娩出を計画し, 救命することが できた. 細心の摘出術および周術期管理を行い, 現時 点で合併症のない救命を得られたが, 未熟奇形腫であ るため, AFP や画像のフォローが必要である.
}

\section{利益相反}

本論文について，開示すべき利益相反（COI）はない.

付 記

本稿の内容は, 第 21 回日本胎児心臓病学会 (2015 年 2 月, 東京) で発表した.

\section{引用文献}

1) Brace V, Grant SR, Brackley KJ, et al: Prenatal diagnosis and outcome in sacrococcygeal teratoma: A review of cases between 1992 and 1998. Prenat Diagn 2000; 20: $51-55$

2) Wilson RD, Hedrick H, Flake AW, et al: Sacrococcygeal teratomas: Prenatal surveillance, growth, and pregnancy outcome. Fetal Diagn Ther 2009; 25: 15-20

3) Usui N, Kitano Y, Sago H, et al: Outcomes of prenatally diagnosed sacrococcygeal teratomas: the results of a Japanese nationwide survey. J Pediatr Surg 2012; 47: 441-447

4) Robal JL, Moldenhauer JS, Khalek N, et al: Early delivery as an alternative management strategy for selected highrisk fetal sacrococcygeal teratomas. J Pediatr Surg 2011; 46: $1325-1332$

5) Hedrick HL, Flake AW, Cromblehlime TM, et al: Sacrococcygeal teratoma: Prenatal assessment, fetal intervention, and outcome. J Pediatr Surg 2004; 39: 430-438, discussion, $430-438$

6) Coleman A, Shaaban A, Keswani S, et al: Sacrococcygeal teratoma growth rate predicts adverse outcomes. J Pediatr Surg 2014; 49: 985-989

7) Coleman A, Kline-Fath B, Keswani S, et al: Prenatal solid tumor volume index: Novel prenatal predictor of adverse outcome in sacrococcygeal teratoma. J Surg Reserch 2013; 184: $330-336$

8) Rodriguez MA, Cass DL, Lazar DA, et al: Tumor volume to fetal weight ratio as an early prognostic classification for fetal sacrococcygeal teratoma. J Pediatr Surg 2011; 46: $1182-1185$

9) Yoneda A, Usui N, Taguchi T, et al: Impact of the histological type on the prognosis of patients with prenatally diagnosed sacrococcygeal teratomas: The results of a nationwide Japanese survey. Pediatr Surg Int 2013; 29: 1119-1125

10) Van Mieghem T, Al-Ibrahim A, Deprest J, et al: Minimally invasive therapy for fetal sacrococcygeal teratoma: Case series and systematic review of the literature. Ultrasound Obstet Gynecol 2014; 43: 611-619

11) Cowles RA, Stolar CJH, Kandel JJ, et al: Preoperative angiopraphy with embolization and radiofrequency ablation as novel adjuncts to safe surgical resection of a large, vascular sacrococcygeal teratoma. Pediatr Surg Int 2006; 22: $554-556$

12）田中秀明，高安 肇，藤野明浩，ほか：巨大仙尾部奇 形腫の新生児期手術と周術期管理. 小児外科 2008; 40: 823-827

13) Lahdes-Vasama TT, Korhonen PH, Seppanen JM, et al: Preoperative embolization of giant sacrococcygeal teratoma in a premature newborn. J Pediatr Surg 2011; 46: E5-E8 
14) Hofstaetter C, Hausmann M, Eik-Nes SH, et al: A cardiovascular profile score in the surveillance of fetal hydrops. J Matern Fetal Neonatal Med 2006; 19: 407-413

15) Donofrio MT, Moon-Grady AJ, Hornberger LK, et al: American Heart Association Adults with Congenital Heart Disease Joint Committee of the Council on Cardiovascular Disease in the Young and Council on Clinical Cardiology, Council on Cardiovascular Surgery and Anesthesia, and Council on Cardiovascular and Stroke Nursing: Diagnosis and Treatment of fetal cardiac disease: A scientific statement from the American Heart Associa- tion. Circulation 2014; 129: 218-242

16) Statile CJ, Cnota JF, Gomien S, et al: Estimated cardiac output and cardiovascular profile score in fetuses with high cardiac output lesions. Ultrasound Obstet Gynecol 2013; 41: 54-58

17) Rychik J: Fetal cardiovascular physiology. Pediatr Cardiol 2004; 25: 201-209

18) Tongsong T, Tongprasert F, Srisupundit K, et al: Venous Doppler studies in low-output and high-output hydrops fetalis. Am J Obstet Gynecol 2010; 203: 488e1-6 